\title{
KARAKTERISTIK GEOTEKNIK MINERAL LEMPUNG PADA TEROWONGAN TAMBANG BAWAH TANAH CIURUG LEVEL 600, PONGKOR, JAWA BARAT
}

\author{
ROBBY GINANJAR, IMAM ACHMAD SADISUN
}

Program Studi Teknik Geologi, Fakultas Ilmu dan Teknologi Kebumian, Institut Teknologi Bandung (ITB), Jl.

Ganesha No.10, Bandung, Jawa Barat, Indonesia. Email: robby.ginanjar@students.itb.ac.id

\begin{abstract}
Sari - Zona argilik pada terowongan tambang bawah tanah Ciurug level 600 memerlukan penanganan dan perhatian khusus pada perkuatan terowongan. Hal ini perlu dilakukan karena zona argilik tersebut secara umum membuat massa batuan disekitar penambangan menjadi lemah. Zona argilik tersebut dapat diidentifikasi secara langsung pada bukaan terowongan atau dari hasil inti pemboran bawah permukaan. Argilitisasi yang terjadi pada bukaan XC 662 dan XC 61a memiliki karakteristik yang berbeda, baik secara persebarannya maupun jenis kehadiran mineral lempungnya. Zona argilik yang hadir pada bukaan XC 662 menunjukan distribusi yang terkonsentrasi di sekitar urat kuarsa, sedangkan pada bukaan XC 6-1a distribusinya lebih merata, sehingga melemahkan hampir di seluruh bagian bukaan terowongan. Karakteristik mineral lempung pada zona argilik di kedua bukaan terowongan diuji menggunakan beberapa pengujian salah satunya adalah uji batas Atterberg. Hasil uji batas Atterberg menunjukan bahwa Indeks Plastisitas (IP) dari mineral lempung pada zona argilik berkisar antara 17,64 - 33,33 dan nilai aktivitas yang berkisar antara 1,1-1,6. Nilai tersebut dipengaruhi oleh mineral lempung berupa kaolinit, vermiculite, smektit, dan halloysite.
\end{abstract}

Kata kunci: Zona argilik, karakteristik, batas Atterberg, nilai aktivitas

\begin{abstract}
Argillic zone in underground mining of Ciurug level 600 need a special handling and attention on tunnel support. The argillic zone is generally decreasing the strength of rock mass on mining site. The zone can be identified directly from tunnel cross cut or coring data of underground drilling. Argillitization on cross cut XC 662 and XC 6 la has their own different characteristics, either on the distribution or the kind of clay minerals appear. The argillic zone on cross cut XC 662 is concentrated around quartz vein, while on cross cut XC 6-1a is well distributed and decreasing the strength of the rock mass in almost the whole part around the cross cut. Clay minerals characteristics in argillic zone on both cross cut are tested using several methods, i.e. Atterberg limit. The results of Atterberg limit test are showing that the Plasticity Index (IP) of clay minerals in argillic zone are ranging from 17,64 - 33,33 and activity ranging from 1,1 - 1,6. These results are affected by clay minerals such kaolinite, vermiculite, smectite, and halloysite.
\end{abstract}

Keywords: Argillic zone, characteristics, Atterberg limit, activity

\section{PENDAHULUAN}

Mineral lempung merupakan mineral yang memiliki perilaku khusus, diantaranya adalah mengembang (swelling) dan menyusut (shrinkage). Perilaku tersebut berhubungan langsung dengan perubahan kadar air pada suatu material yang mengandung mineral lempung (Wesley, 2010). Mineral lempung yang memiliki perilaku khusus berupa mengembang (swelling) diantaranya adalah kelompok smektit (montmorilonit, saponite, beidellite, dsb.), yang kehadirannya perlu diperhatikan, khususnya pada bukaan tambang bawah tanah. Kehadiran mineral lempung tersebut dapat melemahkan massa batuan disekitar bukaan terowongan, sehingga diperlukan penanganan dan perhatian khusus pada massa batuan tersebut. Mineral lempung yang hadir di lokasi penelitian merupakan produk/hasil dari aktivitas hidrotermal atau lebih tepatnya merupakan bagian dari zona alterasi argilik.

Penelitian ini bertujuan untuk mengetahui sifat dan karakteristik mineral lempung yang hadir di sekitar bukaan terowongan XC 662 dan XC 6-1a level 600 tambang bawah tanah Ciurug, Pongkor, Jawa Barat (Gambar 1). 


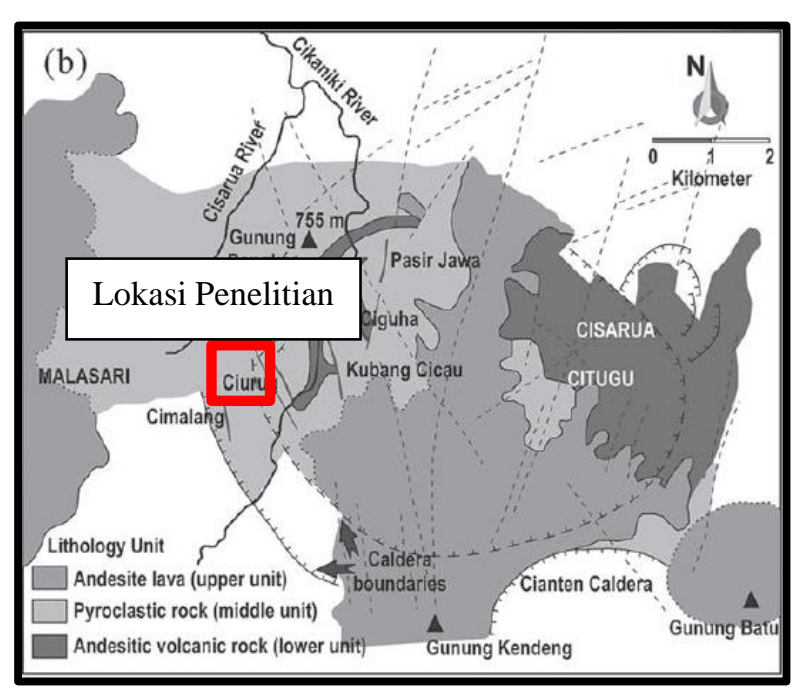

Gambar 1. Lokasi penelitian yang berada pada tambang milik konsesi PT Antam (Persero) Tbk UBPE Pongkor, Ciurug, Pongkor, Jawa Barat (Syafrizal dkk., 2007).

\section{DATA AND METODOLOGI}

\subsection{Data}

Data yang dipergunakan pada penelitian ini diperoleh secara langsung pada bukaan terowongan XC 662 dan XC 6-1a. Secara visual sampel yang diambil memiliki kandungan mineral lempung yang tinggi. Pada bukaan XC 662, sampel diambil pada tuf lapili teralterasi yang posisinya ada pada zona urat kuarsa (Gambar 2).

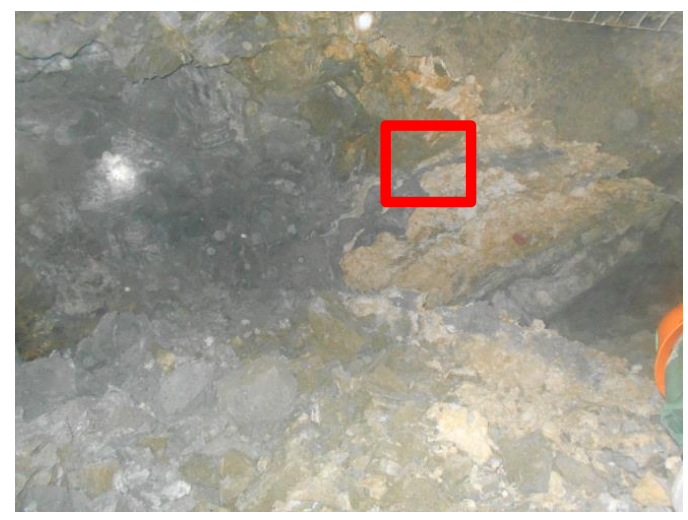

Gambar 2. Lokasi pengambilan sampel pada bukaan XC 662.
Pada bukaan XC 662, mineral lempung terkonsentrasi di bagian hangingwall dekat zona urat, sementara pada bukaan XC 6-1a terdistribusi merata hampir di seluruh bagian bukaan terowongan (Gambar 3), yang dipengaruhi oleh jenis batuan samping berupa tuff lapilli.

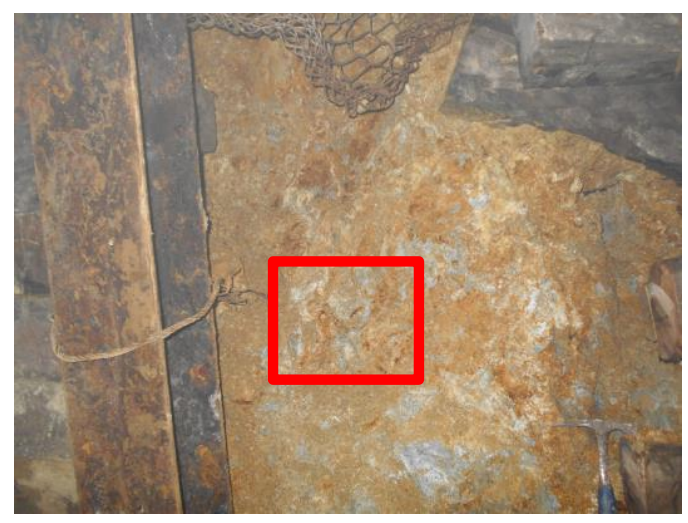

Gambar 3. Lokasi pengambilan sampel pada bukaan XC 6-1a.

\subsection{Metodologi}

4 buah Sampel (masing-masing bukaan 2 sampel) yang diambil dari bukaan terowongan menggunakan pipa PVC berdiameter $10 \mathrm{~cm}$ yang ditancapkan ke dinding terowongan sedalam $30 \mathrm{~cm}$ dan dibungkus menggunakan kertas alumunium foil agar kondisi sampel tetap terjaga seperti kondisi sebenarnya di lapangan. Selanjutnya sampel tersebut dilakukan pengujian di laboratorium, berupa pengujian sifat fisik, analisis besar butir, batas Atterberg, kuat geser langsung, uji swelling, dan analisis XRD (X-Ray Diffraction).

\subsubsection{Uji Sifat Fisik}

Pengujian ini bertujuan untuk mengetahui kadar air alami $(\omega)$, densitas bulk $\left(\gamma_{\mathrm{m}}\right)$, densitas kering $\left(\gamma_{\mathrm{d}}\right)$, berat jenis $\left(\mathrm{G}_{\mathrm{s}}\right)$, angka pori (e), porositas (n), dan derajat kejenuhan (Sr), yang menggunakan standar SNI 032437-1991.

\subsubsection{Analisis Besar Butir}

Analisis ini bertujuan untuk mengetahui distribusi ukuran butir yang terdapat pada material yang terpengaruh oleh alterasi 
argilik. Selain itu, pengujian ini bertujuan untuk mengetahui adanya kandungan material halus untuk pengujian batas Atterberg. Pengujian ini menggunakan standar ASTM D6913-04.

\subsubsection{Batas Atterberg}

Pengujian batas Atterberg ini bertujuan untuk mengetahui nilai batas cair (LL), batas plastis (PL), dan indeks plastisitas (PI). Nilai tersebut digunakan untuk memprediksi kemungkinan pengembangan dan memprediksi jenis mineral lempung yang hadir. Selain itu, jika dikombinasikan dengan hasil analisis besar butir, dapat ditentukan nilai aktivitas (Ac) mineral lempung, yang juga dapat digunakan untuk memprediksi jenis mineral lempung yang hadir. Pengujian ini menggunakan standar ASTM 413 -17e1.

\subsubsection{Uji Kuat Geser Langsung}

Pengujian ini bertujuan untuk mengetahui properti mekanik dari material/batuan utuh yang mengalami alterasi argilik. Parameter yang diperoleh dari pengujian ini adalah nilai kohesi dan sudut geser dalam. Pengujian ini berdasarkan standar ASTM D3080/3080M.

\subsubsection{Uji Swelling}

Pengujian ini bertujuan untuk mengetahui potensi pengembangan yang dapat terjadi dari masing-masing material yang diambil dari kedua bukaan terowongan. Selain itu, pengujian ini berguna untuk memvalidasi hasil dari pengujian batas Atterberg. Pengujian ini menggunakan standar ASTM D4546.

\subsubsection{Analisis XRD}

Sama halnya dengan pengujian swelling, analisis XRD berguna untuk memvalidasi kehadiran jenis mineral lempung pada masingmasing sampel dari kedua bukaan terowongan dan membandingkannya dengan hasil prediksi jenis mineral yang muncul dari nilai indeks plastisitas (PI) dan nilai aktivitasnya (Ac). Analisis ini dilakukan dua kali, yaitu kondisi bulk $(2 \theta=15-65)$ dan clay oriented $(2 \theta=5-$ 35). Dua kondisi ini diperlukan untuk mengidentifikasi kandungan mineral secara umum (bulk) dan kandungan mineral lempung (clay oriented).

\section{HASIL DAN DISKUSI}

Hasil dari pengujian sifat fisik menunjukan bahwa sifat fisik material dari bukaan XC 6-1a, relatif lebih rendah dibandingkan dengan material dari bukaan XC 662. Berikut rangkuman pengujian sifat fisik pada Tabel 1. Hal ini menunjukan bahwa intensitas alterasi mempengaruhi nilai sifat fisik dari massa batuan.

Hasil dari pengujian besar butir menunjukan bahwa material dari bukaan XC 662 terdiri dari partikel halus sejumlah $52,86 \%$ dengan komposisi material lempungnya sekitar $21,07 \%$. Sementara material dari bukaan XC 6-1 terdiri dari material halus sejumlah $52,68 \%$ dan komposisi material berukuran lempung sekitar $16,65 \%$.

Pengujian batas Atterberg memberikan hasil bahwa pada bukaan XC 662 nilai batas cair (LL) sekitar 66,76, batas plastis (PL) 33,42, dan indeks plastisitas (PI) 3,33, yang berdasarkan klasifikasi Casagrande (1948) tergolong pada lanau dengan plastisitas tinggi $(\mathrm{MH})$. Sementara hasil analisis dari bukaan XC 6-1a menunjukan bahwa nilai batas cair (LL) sekitar 46,16, batas plastis (PL) 28,52, dan indeks plastisitas 17,64, yang berdasarkan pada klasifikasi Casagrande (1948) tergolong lanau dengan plastisitas rendah (ML).

Tabel 1. Hasil pengujian sifat fisik dari kedua bukaan terowongan

\begin{tabular}{|c|c|c|c|c|c|c|c|c|}
\hline No. & Sampel & $\begin{array}{c}\omega \\
(\%)\end{array}$ & $\begin{array}{c}\gamma_{\mathrm{m}} \\
\left(\mathrm{gr} / \mathrm{cm}^{3}\right)\end{array}$ & $\begin{array}{c}\gamma_{\mathrm{d}} \\
\left(\mathrm{gr} / \mathrm{cm}^{3}\right)\end{array}$ & $\mathrm{G}_{\mathrm{s}}$ & $\mathrm{e}$ & $\mathrm{n}$ & $\begin{array}{c}\mathrm{Sr} \\
(\%)\end{array}$ \\
\hline 1 & XC 662 & 20 & 1,96 & 1,64 & 2,80 & 0,71 & 0,42 & 78 \\
\hline 2 & XC 6-1a & 40 & 1,78 & 1,28 & 2,75 & 1,15 & 0,54 & 94 \\
\hline
\end{tabular}


berukuran lempung, dapat ditentukan nilai aktivitasnya, seperti pada perhitungan berikut:

$$
A c=\frac{P I}{(\% \text { material berukuran lempung) }}
$$

Sehingga diperoleh nilai aktivitas material lempung pada bukaan XC 662 adalah 1,6 dan XC 6-1a adalah 1,1. Mengacu pada Skempton (1953), nilai aktivitas tersebut menunjukan kehadiran monmorilonit dan ilit. Sementara berdasarkan nilai indeks plastistasnya dan mengacu pada White (1949), mineral lempung yang hadir adalah ilit dan kaolinit.

Dengan karakteristik mineral lempung tersebut, nilai kohesi (c) material pada bukaan XC 662 adalah 0,073 MPa dan sudut geser dalam (Ø) 19,3 ${ }^{\circ}$. Sementara pada bukaan XC 6-1a, nilai c sekitar $0,038 \mathrm{MPa}$ dan $\varnothing$ sekitar $13,8^{\circ}$. Selain itu, persentase pengembangan rata-rata pada bukaan XC 662 adalah sekitar $9,44 \%$, sedangkan pada XC 6-1a adalah $1,52 \%$. Hal ini menunjukan bahwa material pada XC 662 lebih ekspansif dibandingkan XC 6-1a.

Berdasarkan hasil analisis XRD, mineral lempung yang hadir pada bukaan XC 662 adalah halloysite, smektit (monmorilonit, saponite, beidellite), dan kaolinit. Sementara pada bukaan XC 6-1a mineral lempung yang hadir adalah kaolinit dan vermiculite. Hasil ini sesuai dengan prediksi jenis mineral lempung yang hadir, berdasarkan karakteristik geotekniknya. Gambar 4 adalah hasil analisis XRD clay oriented pada bukaan XC 662 dan Gambar 5 adalah hasil analisis XRD clay oriented pada bukaan terowongan XC 6-1a.

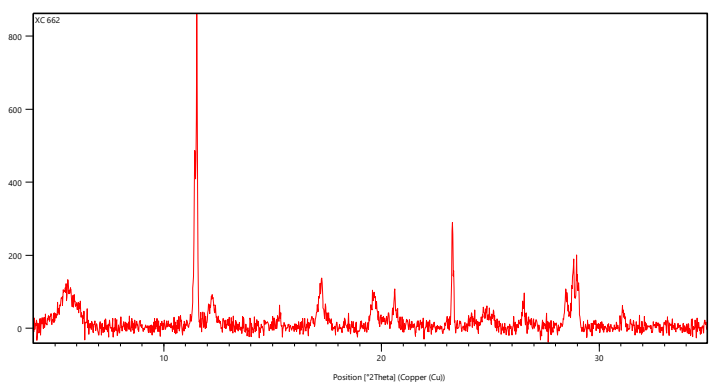

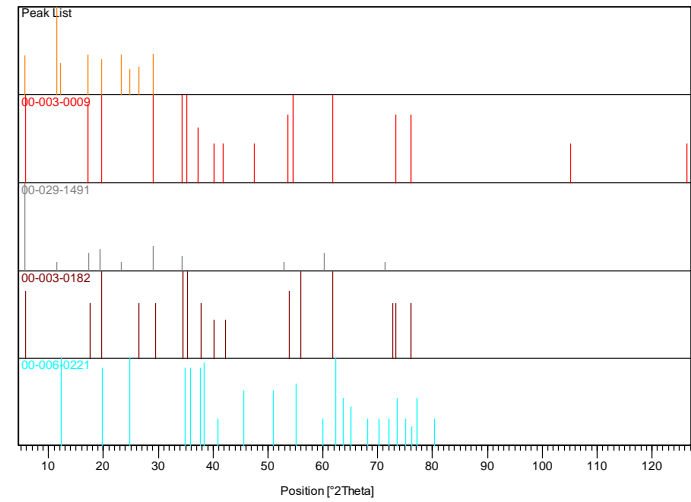

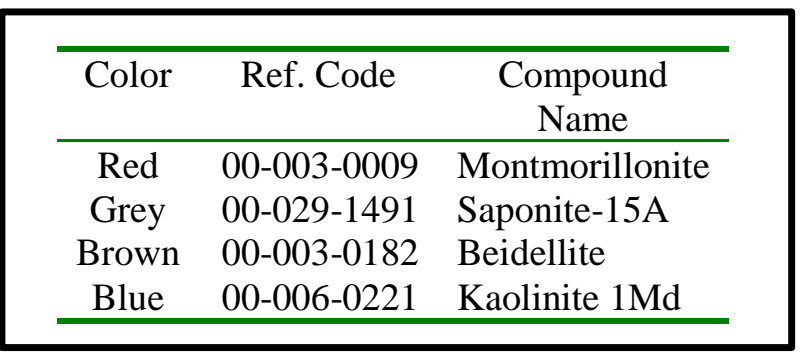

Gambar 4. Hasil analisis XRD clay oriented pada bukaan XC 662.
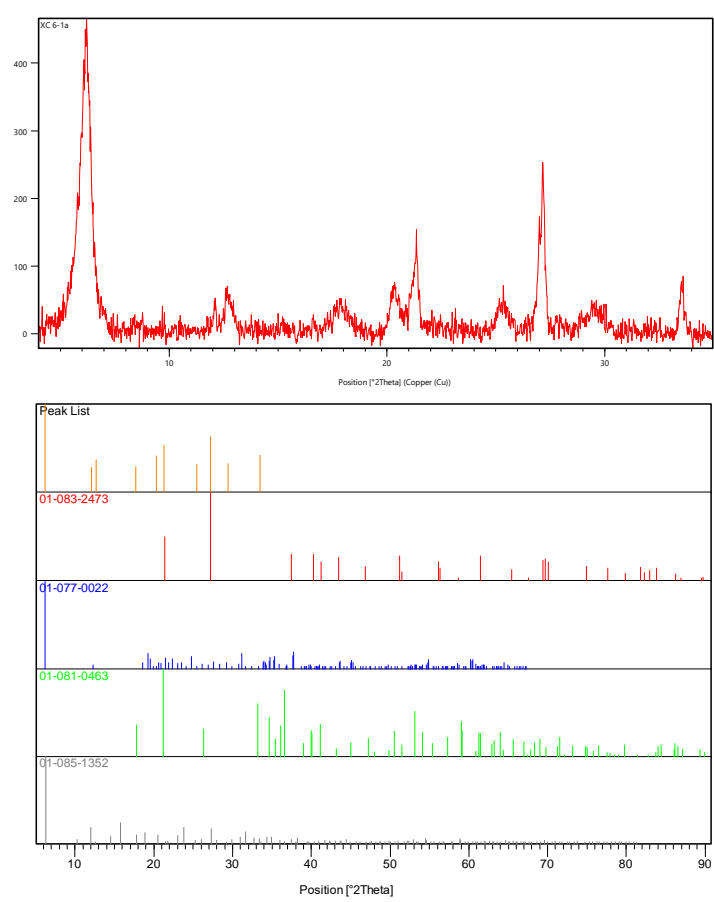

\begin{tabular}{ccc}
\hline Color & Ref. Code & $\begin{array}{c}\text { Compound } \\
\text { Name }\end{array}$ \\
\hline
\end{tabular}

\begin{tabular}{ccl} 
Red & $01-083-2473$ & Quartz low, syn \\
Blue & $01-077-0022$ & Vermiculite \\
Green & $01-081-0463$ & Goethite, syn \\
Grey & $01-085-1352$ & Faujasite nickel \\
& & $\begin{array}{l}\text { m- } \\
\text { dichlorbenzene }\end{array}$ \\
\hline
\end{tabular}

Gambar 5. Hasil analisis XRD clay oriented pada bukaan XC 6-1a. 
Hasil analisis XRD ini memperkuat penyebab tingginya potensi pengembangan dari sampel pada bukaan XC 662. Grup smektit merupakan jenis mineral lempung yang reaktif terhadap air dan memiliki kemampuan ekspansif yang sangat tinggi. Namun karena persentase kehadiran mineral lempungnya tidak terlalu intensif dan terdistribusi merata seperti pada bukaan XC 6-1a, maka nilai pengembangannya hanya sekitar $9,44 \%$. Persentase ini tergolong pada jenis pengembangan yang tinggi (USBR, 1998).

Hal ini bertolak belakang dengan bukaan XC 6-1a. Walaupun intensitas kehadiran dan distribusi mineral lempungnya lebih merata, tetapi karena jenis mineral lempung yang hadir adalah kaolinit dan vermiculite yang tidak reaktif terhadap kandungan air, maka tingkat pengembangannya hanya sekitar $1,52 \%$ saja. Persentase ini tergolong pada jenis pengembangan yang sedang (USBR, 1998).

\section{KESIMPULAN}

Rendahnya nilai hasil pengujian sifat fisik dan tingginya tingkat pengembangan pada material dari bukaan XC 662 disebabkan oleh adanya kehadiran mineral lempung grup smektit, seperti monmorilonit, saponite, dan beidellite. Walaupun proses argilitisasi lebih berkembang pada bukaan XC 6-1a yang ditunjukkan oleh tingginya intensitas kehadiran mineral lempung dan distribusinya yang lebih merata, tetapi jenis mineral lempung yang cukup reaktif justru hadir pada bukaan XC 662, yang kehadiran mineral lempungnya terkonsentrasi di sekitar zona urat kuarsa.

\section{UCAPAN TERIMA KASIH}

Penulis mengucapkan banyak terima kasih kepada PT Antam (Persero) Tbk. UBPE Pongkor, yang telah mengizinkan penulis untuk menggunakan daerahnya sebagai objek penelitian.

\section{DAFTAR PUSTAKA}

United States Bureau of Reclamation (1998): Earth Manual, $3^{\text {rd }}$ edition, Denver,
Colorado.

Casagrande, A. (1948): Classification and identification of soils, Transactions, American Socienty of Civil Engineers, 113, $901-991$.

Skempton, A.W. (1953): The colloidal activity of clays, 3rd International Conference of Soil Mechanics and Foundation Engineering, Switzerland, 1.

Syafrizal, Imai, A., dan Watanabe, K. (2007): Origin of ore-forming fluids responsible for gold mineralization of the Pongkor Au-Ag deposit, West Java, Indonesia: Evidence from mineralogic, fluid inclusion microthermometry and stable isotope study of the Ciurug-Cikoret veins, Resource Geology, 57(2), 136 - 148.

Wesley, L.D. (2010): Mekanika Tanah untuk Tanah Endapan dan Residu, ANDI, Yogyakarta.

White, W.A. (1949): Atterberg Plastic Limits of Clay Minerals, Report of investigation, State of Illinois, USA. 